\title{
Hysteroscopic Evaluation of Abnormal Uterine Bleeding- Vaginoscopic Approach
}

Authors

\section{Major (Dr) Rahul Mahajan, Colonel (Dr) Prasad Lele², Brigadier (Dr) Manash Biswas ${ }^{3}$}

${ }^{1}$ Resident, Dept of Obs \& Gyn, Armed Forces Medical College, Pune

${ }^{2}$ Senior Advisor, Dept of Obs \& Gyn, Command Hospital, Lucknow

${ }^{3}$ Professor \& HOD, Dept of Obs \& Gyn, Armed Forces Medical College, Pune

\begin{abstract}
Introduction: Abnormal uterine bleeding, a common but complicated clinical presentation accounting for almost $20 \%$ of gynecologic outpatient visits 1, reported 25\% of gynecologic surgeries.2Easily accomplished in an office setting with little or no analgesia or anesthesia, office hysteroscopy provides direct access to the uterine cavity giving an accurate diagnosis directing surgical or medical treatment for the specific pathology and may avoid the need for major surgery
\end{abstract}

Aims \& Objectives: Hysteroscopic evaluation of the cervical canal \& uterine cavity in women with AUB to evaluate various causes and to perform diagnostic or therapeutic intervention whenever possible to reach the actual diagnosis and relieve the symptoms in office setting.

Method: 100 cases diagnosed with various presentations of AUB in reproductive and postmenopausal group were evaluated prospectively by office hysteroscopy with vaginoscopy approach between Jan 2014 to Jun 2015 in tertiary care hosp of Pune (Maharashtra). Histopathology examination of endometrium and/or pelvic ultrasound was done in selective cases to reach a final diagnosis.

Results: Office hysteroscopy was successfully carried out in 98 of 100 women, $42 \%$ of these had normal cavity, $13 \%$ had fibroid, $12 \%$ had polyp, $7 \%$ had hyperplastic endometrium, $7 \%$ had adenomyosis, 3\% foreign bodies, 7\% intrauterine adhesions, 2\% tubercular endometritis, $1 \%$ retained products, 1 case of endometrial $C A$ and 2 cases of uterine anomalies.

Total 12 cases (12.24\%) of AUB were treated in the same setting, including six cases of weak intrauterine adhesions, three cases each of small intrauterine polyps and three cases of foreign bodies, in two cases CuT thread was missing whereas the other woman having AUB was unaware about CuT inserted in her uterus long back.

Conclusion: Diagnostic hysteroscopy performed with vaginoscopy approach in an office setting with little discomfort to the patient, enabled the physician to search for organic intrauterine abnormalities and to select the proper form of therapy based on the findings reducing requirement of unnecessary surgical intervention in patients with normal cavity. A small proportion of patients were treated in the same setting for the underlying pathology to relieve the symptoms. With the invention of modern thin caliber, cordless and portable devices, office hysteroscopy will definitely be used as a first step in evaluation of AUB. Keywords: Abnormal uterine bleeding, Office hysteroscopy, Vaginoscopy, Menorrhagia, Polyp, Fibroid. 


\section{Introduction}

Abnormal uterine bleeding (AUB) is one of the commonest problems with which women present to gynecology outpatient department. ${ }^{1}$ The problem can present in a wide variety of clinical types and can be due to multiple unrelated etiologies.

The prevalence of abnormal uterine bleeding, the difficulties in identifying its causes, and the cost of management prompts for reliable diagnostic techniques and treatment strategies as it often leads to medical and surgical strategies that focus on correcting symptoms or providing treatment without first making a definitive diagnosis. An ideal approach would promptly identify patients with organic disease, facilitate patient comprehension and choice of treatment options, improve treatment efficacy, and reduce overall cost of care.

Easily accomplished in an office or outpatient setting with little or no analgesia or anesthesia, hysteroscopy provides direct access to the uterine cavity. Intrauterine magnified visualization when displayed on a video screen encouraged and facilitates patient-physician dialogue, allowing thorough informed consent regarding subsequent medical or surgical interventions. Moving the procedure from hospital operation theatre setting to physician's office significantly reduces the cost too. ${ }^{2}$

Diagnostic hysteroscopy and simple operative hysteroscopy can usually be done in an office setting. ${ }^{3}$ An accurate diagnosis may result in surgical or medical treatment directed at the specific pathology and may avoid the need for major surgery. This article reviews the history, instrumentation, diagnostic and operative techniques, and potential complications of hysteroscopy in the management of abnormal uterine bleeding.

\section{Material and Methods}

This is a prospective study carried out in outpatient department of Command Hospital (Southern Command), associated with Armed
Forces Medical College, Pune between Jan 2014 to Jun 2015.

Ethical approval for the study was obtained from College research ethics committee prior to embarking on the study.

Total 1188 of 17054 women attending gynecology OPD presented with complaints of menstrual irregularity making an incidence of $7 \%$ of AUB in the study population.

Women in Reproductive \& Postmenopausal age with AUB who attended the Gynecology OPD on Thursdays were subjected to a thorough physical examination and routine investigations like $\mathrm{Hb} \%$, blood sugar, urine routine \& microscopy, HIV, HBSAg, Anti HCV followed by hysteroscopy after obtaining post counseling informed consent.

The procedure was performed in office hysteroscopy room. No preprocedure medication or analgesia/anesthesia was given though tab misoprostol 200 microgram was applied by the women 3 to $4 \mathrm{hrs}$ prior to undergoing this procedure. Vaginoscopy approach was adapted by avoiding primary instrumentation before inserting the scope into vagina. Instruments were used only in cases requiring some diagnostic/therapeutic intervention. Histopathology examination of endometrium was done in selective cases to reach a final diagnosis. Following women were excluded from the study:

- Pregnancy/Abortions/Ectopic pregnancy

- Uterine and cervical infections and PID

- STD's and vaginitis

- Lower genital tract malignancies

- Medical contraindications to any invasive procedures

\section{Observation}

A total 100 patients were included in the study. Mean age of presentation was 42 years, 96 were premenopausal and 04 were postmenopausal. 09 women among the premenopausal age group were nulligravida. (Table 1) 
Table-1 Age Distribution of Patients with AUB $(n=100)$

\begin{tabular}{|l|c|c|c|}
\hline \multirow{2}{*}{$\begin{array}{l}\text { Age } \\
\text { Distribution }\end{array}$} & \multicolumn{2}{|c|}{ \% of Patients } & Nulligravida \\
\cline { 2 - 3 } & Premenopausal & Postmenopausal & \\
\hline $20-25$ & 3 & - & 2 \\
\hline $25-30$ & 8 & - & 4 \\
\hline $30-35$ & 11 & - & 1 \\
\hline $35-40$ & 14 & - & 1 \\
\hline $40-45$ & 30 & - & 1 \\
\hline $45-50$ & 24 & - & - \\
\hline $50-55$ & 6 & 1 & - \\
\hline $55-60$ & - & 2 & - \\
\hline $60-65$ & - & 1 & - \\
\hline
\end{tabular}

Out of 100 hysteroscopies carried out, 98 were successful. The unsuccessful hysteroscopy were due to excessive bleeding which clouded the field and hence impaired visibility in one case and another case was abandoned because of excessive pain experienced by the patient.

In the study population, menorrhagia was the most common presenting complaint in 72 women $(70.56 \%)$ followed by dysmenorrhea in 23
(22.54\%), Hypomenorrhea, oligomenorrhea and polymenorrhea were present in 21 women (20.74\%), metrorrhagia in 06 (5.88\%), metropathica hemorrhagica in 02 whereas only 04 women presented with postmenopausal bleeding. Many of the patients had more than one type of bleeding which gave a multifaceted presentation. (Table-2)

Table-2 Type of Complaint (Presentation)

\begin{tabular}{|l|l|c|c|}
\hline Sr No & Type of Bleeding & Total No(n=100) & $\%$ \\
\hline 1 & Menorrhagia & 72 & 70.56 \\
\hline 2 & Dysmenorhoea & 23 & 22.54 \\
\hline 3 & Hypomenorrhoea & 09 & 8.82 \\
\hline 4 & Oligomenorrhoea & 08 & 7.84 \\
\hline 5 & Polymenorrhoea & 04 & 4.08 \\
\hline 6 & Metrorrhagia & 06 & 5.88 \\
\hline 7 & Metroapathia hemorrhagica & 02 & 2.04 \\
\hline 8 & Post menopausal bleeding & 04 & 4.08 \\
\hline
\end{tabular}

Many of the patients had more than one type of bleeding

In our study, $42 \%$ of these women had normal cavity, $13 \%$ had fibroid, $12 \%$ had polyp, $7 \%$ had hyperplastic endometrium, $8 \%$ had adenomyosis, $2 \%$ had foreign bodies, $7 \%$ had intrauterine adhesions, $2 \%$ tubercular endometritis, $1 \%$ retained products, 1 case of endometrial $\mathrm{CA}$ and 2 cases of uterine anomalies (Table-3). Histopathology examination of endometrium was done in selective cases to reach final diagnosis. 
Table-3 Total Hysteroscopic Findings

\begin{tabular}{|l|l|l|l|}
\hline Sr No & Findings & Total No(n=98) & \% \\
\hline 1 & Normal cavity & $\mathbf{4 2}$ & 42.86 \\
\hline 2 & Fibroid & $\mathbf{1 3}$ & 13.27 \\
\hline 3 & Polyps & $\mathbf{1 2}$ & 12.24 \\
\hline 4 & Fibroid+ Polyp & $\mathbf{1}$ & 1.02 \\
\hline 5 & Hyperplastic Endometrium** & $\mathbf{7}$ & 7.14 \\
\hline 6 & Adenomyosis* & $\mathbf{7}$ & 7.14 \\
\hline 7 & Foreign Bodies & $\mathbf{3}$ & 3.06 \\
\hline 8 & Intrauterine adhesions & $\mathbf{7}$ & 7.14 \\
\hline 9 & Tubercular Endometritis** & $\mathbf{2}$ & 2.04 \\
\hline 10 & Retained products of conception** & $\mathbf{1}$ & 1.02 \\
\hline 11 & Endometrial CA** & $\mathbf{1}$ & 1.02 \\
\hline 12 & Uterine Abnormalities & $\mathbf{2}$ & 2.04 \\
\hline
\end{tabular}

*Confirmed with ultrasound as an adjunctive method

**Confirmed with histopath report of biopsy specimen

Findings as per FIGO classification system for causes of AUB

As per new FIGO nomenclature 84 of these 100 women presented with heavy menstrual bleeding (HMB), 9 had light bleeding (less than $5 \mathrm{ml} /$ day), 8 infrequent bleeding (cycle $>38$ days), 4 had frequent bleeding (cycle $<24$ days)

Table-4: AUB Presentation as per FIGO (2011)

\begin{tabular}{|l|c|c|c|}
\hline Sr No & Presentation & $\begin{array}{c}\text { Total No } \\
(\mathbf{n = 1 0 0})\end{array}$ & $\mathbf{\%}$ \\
\hline 1 & HMB & 84 & 84 \\
\hline 2 & Light bleeding & 09 & 09 \\
\hline 3 & Frequent bleeding & 04 & 04 \\
\hline 4 & Infrequent bleeding & 08 & 08 \\
\hline
\end{tabular}

The causes of AUB as per new FIGO classification can be tabulated as below

Table-5: Findings in AUB as per FIGO (2011)

\begin{tabular}{|l|l|}
\hline Cause of AUB & Total No $(\mathbf{n = 9 8})$ \\
\hline Structural & \\
\hline AUB-P & 12 \\
\hline AUB-A & 07 \\
\hline AUB-L & 13 \\
\hline AUB-M & 08 \\
\cline { 1 - 1 } Nonstructural & \\
\cline { 1 - 1 } AUB-C & \multirow{2}{*}{ Normal cavity-42 } \\
\cline { 1 - 2 } AUB-O & \\
\hline AUB-E & 03(CuT) \\
\hline AUB-I & Anomalies-2, Endometritis-2 Adhesions-7 \\
\hline AUB-N &
\end{tabular}




\section{Interventions/procedure done}

Total 12 cases $(12.24 \%)$ with benign intrauterine pathologies like small polyps, CuT and flimsy adhesions were successfully treated in the same setting with the help of few instruments like small artery forcep, karman's cannula and the tip of the endoscope itself to break the thin adhesions, without subjecting the individuals to the risk of anesthesia avoiding hospital stay and additional expenditure for treatment.

Table-6 : Interventions/Procedures

\begin{tabular}{|l|l|l|}
\hline Sr No & Interventions/Procedures & Total $(\mathrm{n}=98)$ \\
\hline 1 & Small endometrial polyps & 03 \\
\hline 2 & Foreign bodies(CuT) & 03 \\
\hline 3 & Adhesiolysis & 06 \\
\hline Total & & $12(12.24 \%)$ \\
\hline
\end{tabular}

The complications noted were on minor scale, cases of vasovagal attack (Post procedure), one case each of vomiting and intolerable pain, were managed conservatively either with oral NSAID or anti-emetics.

\section{Discussion}

A descriptive nonrandomized study for evaluation of abnormal uterine bleeding using office hysteroscopy with vaginoscopy approach was carried out at tertiary care teaching hospital and medical college. 100 consecutive patients with abnormal uterine bleeding attending gynecology OPD were selected after obtaining a basic history and investigations, and ruling out contraindications and cases with exclusion criteria. No specific method of randomization was used.

There has been a growing interest world over in carrying out the hysteroscopic examination of the uterine cavity as an outpatient procedure. Its sensitivity and specificity in detecting intrauterine abnormalities have been well recognized. $19,20,21,25,26,29$ A number of studies have been carried out to recognize the advantages of this procedure. In this study the main aspects studied were the various findings in the study population, visibility achieved during the procedure and the complications noted in addition to few cases which could be managed in the same office setup without taking the patient to OT.

In the study population, mean age of the women with AUB was 42 years as compared to other studies, like Moawad et al $(2014)^{2}$ with an average age of 47 years, Guin et al $(2011)^{54}$ with 40 years and Chaudhari et al $(2014)^{51}$ with 44 years. Our study included $4 \%$ postmenopausal and $96 \%$ premenopausal women, which included 09 nulligravidas, where as Moawad et al (2014) included $18 \%$ postmenopausal, $82 \%$ premenopausal and $15 \%$ nulligravid women. The other similar study by Guin et al (2011) has 2\% postmenopausal, $98 \%$ premenopausal including $4 \%$ nulligravid women. Chaudhary et al(2014) included 27 nullipara, 44 multipara and 27 grand multipara women including 10 postmenopausal women.

$58 \%$ of women in this study had hemoglobin $>10$ gm $\%, 42 \%$ had $\mathrm{Hb}$ between 7 to $10 \mathrm{gm} \%, 7$ had $\mathrm{Hb}$ less than $7 \mathrm{gm} \%$ and 4 of them required blood transfusion because of very severe anemia.

In this study menorrhagia was the most common presenting complaint in 72 women(70.56\%) followed by dysmenorrhea in 23(22.54\%), Hypomenorrhea, oligomenorrhea and polymenorrhea were present in 21 women (20.74\%), metrorrhagia in 06(5.88\%), metropathica hemorrhagica in 02 whereas only 04 women presented with postmenopausal bleeding. Many of the patients had more than one type of bleeding, which gave a multifaceted presentation. Other comparable studies by Jotsna et al $(2004)^{53}$ and Guin et al(2011) described menorrhagia as the predominant symptom in $56 \%$ and $46 \%$ of the study population, respectively whereas postmenpausal bleeding was present in $6 \%$ and $2 \%$ of the study population respectively. Chaudhari et al (2014) documented menorrhagia in $40 \%$ followed by metrorrhagia in $20 \%$ cases. 
Hysteroscopic findings in patients with menorrhagia in our study included observations like normal cavity in $43 \%$, fibroids in $18 \%$, polyp in $16 \%$, fibroid-polyp in $1 \%$, hyperplastic endometrium in $8 \%$, adenomyosis in $5 \%$ cases, 3 cases of foreign bodies (CuT) and 2 cases of the bicornuate uterus. In study by Jotsna(2004) 30 patients presented with this complaint and the various findings included polyp in 7 cases, myoma in 8 , hyperplastic endometrium in 9 and subseptate uterus and forgotten IUCD in 1case each. Guin et al(2011) recorded 12 cases each of hyperplastic endometrium and polyp, 2 had fibroids, 4 had CuT and 2 had normal cavity. Chaudhari et al (2014) documented hyperplasia in 18 cases, polyp in 10 and myoma in 6 cases.

Dysmenorrhea as a presentation had normal hysteroscopic finding in 35\% cases, polyps in $9 \%$ cases, fibroid in $22 \%$, adenomyosis in $26 \%$ and hyperplastic endometrium in $9 \%$ cases. Other major studies did not mention dysmenorrhea as a distinct presentation.

In our study 09 patients had hypomenorrhea as their presenting complaint. This abnormal bleeding was dominated by intrauterine adhesions as their principle abnormal finding. Guin et al (2011) recorded 12 cases of hypomenorrhea where 2 cases had hyperplastic endometrium, 6 had polyp and 6 had normal uterine cavity on hysteroscopy.

Oligomenorrhoea featured as a complaint in 8 patients, normal cavity was found in 8 of them. The rest mainly had adhesions and findings suggestive of tubercular endometritis. Guin et al (2011) had total 18 cases of oligomenorrhea, 2 had adhesions, 10 had atrophic endometrium and 6 had normal cavity.

Polymenorrhea was the presenting feature in four cases. The only abnormal finding was that of a polyp in one case. The other three patients had normal findings. Jotsna (2004) recorded 12 cases of Polymenorrhea but no intrauterine pathologies were detected on hysteroscopic examination. Guin et al (2011), in this group had 2 CuT, 2 Polyp, 4 cases of fibroid and 4 had a normal uterine cavity.
Chaudhari et al (2014) documented 15 cases of polymenorrhea all of which had normal findings on hysteroscopy.

Metrorrhagia was found in 06 cases. Abnormal findings were demonstrated in 05 cases. Hyperplastic endometrium was seen in 02 of 06 cases while polyp, fibroid and foreign body was seen in remaining three while $28 \%$ showed a normal cavity. Jotsna (2004) recorded 15 cases of metrorrhagia out of which 3 had hyperplastic endometrium, 3 had polyp, myoma in 2 and intrauterine adhesions in 2 cases. Guin et al (2011) had 6 cases of hyperplastic endometrium, 6 had fibroid, 2 had polyp, 2 had atrophic endometrium and 1 had CuT. Chaudhari et al (2014) documented 19 cases with metrorrhagia out of which 8 had normal cavity, 3 had hyperplasia and 4 cases each of myoma and polyp.

Metropathica hemorrhagica was demonstrated in 02 cases, of which one showed normal findings, whereas other revealed findings suggestive of hyperplastic endometrium.

In our study 4 patients had presented with postmenopausal bleeding of which 01 had carcinoma endometrium whereas rest 03 had a normal cavity with atrophic/senile changes in our study. Jotsna (2004) had 6 cases of postmenopausal bleeding wherein 2 had hyperplastic endometrium, 2 had polyp, 1 case each of myoma and endometrial carcinoma. Guin et al (2011) recorded only 2 patients with postmenopausal bleeding and they had atrophic endometrium on evaluation. Chaudhari et al (2014) documented 10 cases of postmenopausal bleed where 2 had hyperplasia, 2 had myoma, 2 cases of atrophy and 4 cases of malignancy were detected.

In our study, $42 \%$ of women had a normal cavity suggesting $58 \%$ pathology detection rate as compared to other studies with pathology detection rate of $47 \%$ by Van Dongen $(2007)^{55}$, $64 \%$ by Moawad (2014), 66\% by Jotsna (2004), and $74 \%$ of Guin et al (2011), here it is important to mention that $18 \%$ of patients included by Guin in pathological finding group had atrophic 
endometrium. Chaudhari et al (2014) documented pathology detection rate of $69 \%$ on hysteroscopy. This indicated that the findings in our study were more or less consistent with findings from other few similar studies.

While talking about specific pathologies, in our study, $13 \%$ women had fibroid, $12 \%$ had polyp, $7 \%$ had hyperplastic endometrium, $8 \%$ had adenomyosis, $2 \%$ had foreign bodies, $7 \%$ had asherman syndrome, $2 \%$ tuberculous endometritis, $1 \%$ retained products, 1 case of endometrial CA and 2 cases of uterine anomalies. Other similar studies showed fibroids in 15\% (Moawad, 2014), 24\% (Van Dongen2007), 17\% (Jotsna, 2004), $16 \%$ (Guin et al,2011), polyps in $32 \%$ (Moawad,2014), 30\% (Van Dongen2007), 20\% (Jotsna, 2004), 28\% (Guin et al, 2011) and $14 \%$ IN Chaudhari et al (2014).

Hyperplasia was described by Moawad in $8 \%$ patients, whereas Jotsna et al and Guin et al described it in $20 \%$ and $30 \%$ of study population respectively, Chaudhari et al (2014) documented hyperplasia in 29 cases. Adenomyosis was described by Towbin in $11 \%$ and by Shwayder in $2 \%$ of the study population. Adhesions were detected in $7 \%$ by Guin et al. Misplaced/missing $\mathrm{CuT}$ causing menorrhagia/ dysmenorrheal was found in 2\% by Moawad (2014). Retained products of conception were found in $1 \%$ by Guin et al whereas endometrial carcinoma was detected in $1.3 \%$ and $1.35 \%$ of study population by Jotsna (2004) and Motashaw respectively, Chaudhari et al (2014) documented malignancy in approximately $4 \%$ cases. Uterine anomalies were detected in $2 \%$ and $2.6 \%$ by by Moawad and Jotsna respectively.

The possible difference in the percentage of findings is due to the fact that only excessive bleeding disorders were considered in other studies. Our study considered all types of abnormal uterine bleeding including hypomenorrhoea, oligomenorrhoea and dysmenorrhea. This could have led to the possible difference in the hysteroscopic findings.
Though the primary aim of this study was diagnostic evaluation of AUB, we also successfully attempted therapeutic interventions to relieve the symptoms of the patient 12 patients $(12.24 \%)$ with benign pathologies by carrying out minor procedures in the same office setting without using resectoscopes, avoiding further operative intervention. Bettocchi et al $(2002)^{52}$, managed 47 to $79 \%$ of patients with relatively smaller intrauterine pathology in outpatient operative hysteroscopy using a thin resectoscope with bipolar electrode.

In our study total two procedures were abandoned (2\% Failure rate), first because of unbearable pain and the second because of clouding of vision because of hemorrhage in the field.. Other similar studies had a failure rate of $7 \%$ in study by Moawad et al (2014) where all the failures were because of inadequate visualization. Our study being unique in using vaginoscopy approach for hysteroscopy had very low failure rate as it caused significantly less pain due to less instrumentation. This study confirms the well known fact that outpatient hysteroscopy offers an acceptable alternative to procedures under general anesthesia. The patients included in this study were not randomly selected but represents a vast majority of women requiring evaluation for abnormal uterine bleeding. Elderly and infirm patients appeared to tolerate the procedure with ease.

An attempt was also made to study the complications caused by the procedure. Though literature identified a long possible list of complications that could be caused by the procedure, the main ones being Trauma, Perforation, Infection and Distension media complications, no major complications were encountered in our study of 100 cases. However, three cases experienced minor complications.

- Vaso-vagal attack: this complication was seen in solitary case and was seen immediately after the end of the procedure. The patient responded satisfactorily to symptomatic treatment. 


\section{JMSCR Vol||4||Issue||01||Page 9042-9053||January}

- Vomiting: solitary case responded satisfactorily to IV antiemetic.

- Acute pain: this was seen in a patient of oligomenorrhea who also was a case of infertility. The patient reported to the nearby private clinic the same late night with complaints of pain abdomen and fever and was sent back after conservative management. The patient followed up in OPD the next morning and managed with NAIDS and antibiotics to treat the acute PID.

A similar study by Guin (2011) showed only three minor complications which were managed conservatively whereas Moawad (2014) had one minor and one major (Uterine perforation) complication during their study, the perforation was subsequently managed in the OT setting.

Hysteroscopy plays an undoubted role in detection of intrauterine abnormalities. The simplicity of this procedure in reaching a conclusive diagnosis in a single OPD visit has probably led to its popularity. The researchers in the past had noted, many interesting findings and these are tabulated as follows. Our study does not differ significantly in the findings when compared to other similar studies.

Table-7: Hysteroscopic findings in various studies

\begin{tabular}{|l|l|l|l|l|l|l|l|l|}
\hline $\begin{array}{l}\text { Study Findings } \\
(\% / N o)\end{array}$ & Normal & Myoma & Polyp & $\begin{array}{l}\text { Myoma } \\
\text { + Polyp }\end{array}$ & $\begin{array}{l}\text { Hyperplasi } \\
\text { a }\end{array}$ & Cancer & $\begin{array}{l}\text { Adenomy } \\
\text {-osis }\end{array}$ & Others \\
\hline Indman n= 243 & $41(97)$ & $31(75)$ & $20(47)$ & $3(8)$ & $2(5)$ & $1(2)$ & $0(0)$ & $2(4)$ \\
\hline Shwayder n=50 & $46(23)$ & $28(14)$ & $16(8)$ & $0(0)$ & $6(3)$ & $0(0)$ & $2(1)$ & $2(4)$ \\
\hline Towbin n=149 & $24(35)$ & $33(49)$ & $22(33)$ & $5(7)$ & $4(6)$ & $0(0)$ & $11(17)$ & $1(2)$ \\
\hline Loffer n=187 & $59.4(111)$ & $11.2(21)$ & $16(30)$ & - & $8.6(16)$ & $3.2(6)$ & - & $1.6(3)$ \\
\hline Jotsna (2004) $)^{53}$ & $34(25)$ & $17(12)$ & $20(15)$ & & $22(16)$ & $1.3(1)$ & & \\
\hline Motashaw G (2011) & 33 & 11.3 & 21.5 & - & 23 & 1.35 & - & 7.3 \\
\hline $\begin{array}{l}\text { Guin G } \\
\text { n=100 }\end{array}$ & 16 & 28 & - & 30 & - & - & 30 \\
\hline $\begin{array}{l}\text { Chaudhary (2014) } \\
\text { N=98 }\end{array}$ & 31 & 16 & 17 & & 29 & 4 & & \\
\hline $\begin{array}{l}\text { Moawad (2014) } \\
\text { N=130 }\end{array}$ & $36(47)$ & $15(20)$ & $32(42)$ & $5(7)$ & $8(10)$ & & & \\
\hline $\begin{array}{l}\text { Our study N=100 } \\
42.87(42)\end{array}$ & $\begin{array}{l}13.26 \\
(13)\end{array}$ & $\begin{array}{l}12.24 \\
(12)\end{array}$ & $1.2(1)$ & $7.14(7)$ & $1.02(1)$ & $8.16(8)$ & $14.28(14)$ \\
\hline
\end{tabular}

\section{Conclusion}

Abnormal uterine bleeding is a common but complicated clinical presentation accounting for almost $20 \%$ of visits to physician offices for gynecologic conditions ${ }^{1}$ and reported $25 \%$ of gynecologic surgeries. $^{2}$

Gynecologic endoscopy (laparoscopy and hysteroscopy) has become an indispensable aid in the diagnosis of abnormal uterine bleeding since it was introduced four decades ago. During last 20 years, endoscopic procedures have been used with increasing frequency as they offer numerous advantages.

Hysteroscopy provides a simple \& an easy method for visualization of the cervical canal \& uterine cavity. It can also be used for treating different kinds of benign pathologies. Contemporary instrumentation permits the gynecologist to acquire quickly the basic skills necessary for routine performance of office-based hysteroscopy. Diagnostic, panoramic hysteroscopy performed in an office setting, with vaginoscopy approach, causes little discomfort to the patient. The procedure enables the physician to search for organic intrauterine abnormalities and to select the proper form of therapy based on the observations. Often no pathology is seen and further surgical interventions are not needed. Few benign pathologies can be treated in the same setting reducing cost, time and anesthetic complications 
to the patient. This procedure currently represents the state of art for investigation of the endometrial cavity. In the future, with the invention of portable, cordless hysteroscopes with disposable sheaths, it will surely become standard of care as the first step for evaluation of causes of abnormal uterine bleeding in selected patients.

\section{Bibliography}

1. Nicholson WK, Ellison SA, Grason H, Powe NR. Patterns of ambulatory care use for gynecologic conditions: a national study. Am J Obstet Gynecol2001;184:52330.

2. Nash S. Moawad, Estefania Santamaria, BS, Megan Johnson, Jonathan Shuster. Cost-Effectiveness of Office Hysteroscopy for Abnormal Uterine Bleeding, JSLS, DOI: 10.4293/JSLS.2014.00393, Source: PubMed

3. Bettocchi S, Di Spiezio Sardo A, Ceci O, Nappi L, Guida M, Greco E, Pinto L, Camporiale AL, Nappi C. A new hysteroscopic technique for the preparation of partially intramural myomas in office setting (OPPIuM technique): A pilot study. J Minim Invasive Gynecol. 2009 Nov-Dec; 16(6):748-54.

4. Thomas Ro“mer, Andreas D. Ebert. Thomas Romer Diagnostic Hysteroscopy, $2^{\text {nd }}$ edition, 2010, Walter de Gruyter GmbH \& Co. KG, Berlin/New York.

5. Liselotte Mettler, M. Parikh, Thoralf Schollmeyer. Diagnostic and Operative hysteroscopy, Society of laparoscopic surgeon, Prevention and management of laparoendoscopic surgical complications $3^{\text {rd }}$ edition, 2012, Chapter-42

6. Goodman A. Abnormal genital tract bleeding. Clin Cornerstone 2000;3:25-35.

7. Hill NC, Oppenheimer LW, Morton KE. The aetiology of vaginal bleeding in children. A 20-year review. Br J Obstet Gynaecol 1989;96:467-70.
8. Livingstone M, Fraser IS. Mechanisms of abnormal uterine bleeding. Hum Reprod Update 2002;8:60-7.

9. Lethaby A, Farquhar C, Sarkis A, Roberts H, JepsonR, Barlow D. Hormone replacement therapy in postmenopausal women: endometrial hyperplasiaand irregular bleeding. Cochrane Database Syst Rev2003;(4):CD000402.

10. Speroff L, Glass RH, Kase NG. Clinical gynecologic endocrinology and infertility. 6th ed. Baltimore: Lippincott Williams \& Wilkins, 1999:201-38,499,575-9.

11. Shwayder JM. Pathophysiology of abnormal uterine bleeding. Obstet Gynecol Clin North Am 2000;27:219-34.

12. Oriel KA, Schrager S. Abnormal uterine bleeding. Am Fam Physician 1999;60:1371-80.

13. Malcolm G. Munro, Hilary O.D. Critchley, Michael S. Broader, Ian S. Fraser: For FIGO working group on menstrual disorder. FIGO classification system (PALM COEIN) for causes of abnormal uterine bleeding in non gravid women of reproductive age. Fertil Steril 2007; 87(3): 466-76,Hum Reprod 2007; 22(3): 635-43

14. Apgar BS. Dysmenorrhea and dysfunctional uterine bleeding. Prim Care 1997;24:161-78.

15. Goldstein SR, Zeltser I, Horan CK, Snyder JR, Schwartz LB. Ultrasonography-based triage for perimenopausal patients with abnormal uterine bleeding. Am J Obstet Gynecol 1997;177:102-8.

16. ACOG practice bulletin no-28: Clinical management guidelines for obstetriciangynecologists. Use of botanicals for management of menopausal symptoms. Obstet Gynecol 2001;96(6 suppl):1-11.

17. Luca Mencaglia, Luiz Cavalcanti de Albuquerque neto, R. Alfonso arias alvarez. Manual of hysteroscopy, Diagnostic, Operative and Office hysteroscopy. Endopress 2013, Germany. 
18. Valle R, Glob. libr. women's med.,Hysteroscopy,

Contact Hysteroscopy, and Microhysteroscopy. ISSN: 1756-2228) 2008; DOI 10.3843/ GLOWM. 10087

19. Clark TJ, Mann CH, Shah N, Khan KS, Song F, Gupta JK. Accuracy of outpatient endometrial biopsy in the diagnosis of endometrial cancer: a systematic quantitative review. BJOG 2002;109:31321.

20. Dijkhuizen FP, Mol BW, Brolmann HA, Heintz AP. The accuracy of endometrial sampling in the diagnosis of patients with endometrial carcinoma and hyperplasia:a meta-analysis. Cancer 2000;8:1765-72.

21. Tabor A, Watt HC, Wald NJ. Endometrial thickness as a test for endometrial cancer in women with postmenopausal vaginal bleeding. Obstet Gynecol 2002;99:663-70.

22. Medverd JR, Dubinsky TJ. Cost analysis model: US versus endometrial biopsy in evaluation of peri- and postmenopausal abnormal vaginal bleeding, Radiology 2002;222:619-27.

23. Clark TJ, Voit D, Gupta JK, Hyde C, Song F, Khan KS. Accuracy of hysteroscopy in the diagnosis of endometrial cancer and hyperplasia: a systematic quantitative review. JAMA 2002;288:1610-21.

24. De Vries LD, Dijkhuizen FP, Mol BW, Brolmann HA, Moret E, Heintz AP. Comparison of transvaginal sonography, saline infusion sonography, and hysteroscopy in premenopausal women with abnormal uterine bleeding. J Clin Ultrasound 2000;28: 217-23.

25. Krampl E, Bourne T, Hurlen-Solbakken H, Istre O. Transvaginal ultrasonography, sonohysterography and operative hysteroscopy for the evaluation of abnormal uterine bleeding. Acta Obstet Gynecol Scand 2001;80:616-22.

26. Widrich T, Bradley LD, Mitchinson AR, Collins RL. Comparison of saline infusion sonography with office hysteroscopy for the evaluation of the endometrium. Am J Obstet Gynecol 1996;174: 1327-34.

27. O'Connell LP, Fries MH, Zeringue E, Brehm W. Triage of abnormal postmenopausal bleeding: a comparison of endometrial biopsy and transvaginal sonohysterography versus fractional curettage with hysteroscopy. Am J Obstet Gynecol 1998;178:956-61.

28. Mihm LM, Quick VA, Brumfield JA, Connors AF Jr, Finnerty JJ. The accuracy of endometrial biopsy and saline sonohysterography in the determination of the cause of abnormal uterine bleeding. Am J Obstet Gynecol 2002;186:858-60.

29. Ben-Yehuda OM, Kim YB, Leuchter RS. Does hysteroscopy improve upon the sensitivity of dilatation and curettage in the diagnosis of endometrial hyperplasia or carcinoma? Gynecol Oncol 1998; 68:4-7.

30. Tahir MM, Biqriqq MA, Browning JJ. A randomized controlled trial comparing transvaginal ultrasound, outpatient hysteroscopy and endometrial biopsy with inpatient hysteroscopy and curettage. Br J Obstet Gynaecol, 1999;106:1259-64.

31. Gianninoto A, Morana C, Campione C. Diagnostic hysteroscopy in abnormal uterine bleeding. Five years experience. Mineva Ginecol. 2003;55:57-61

32. Sciarra JJ, Valle RF. Hysteroscopy: a clinical experience with 320 patients. Am J Obstetet Gynecol. 1977;127:340-8.

33. Smith-Bindman R, Kerlikowske K, Feldstein VA, Subak L, Scheidler J, Segal M1. Endovaginal ultrasound to exclude endometrial cancer and other endometrial abnormalities. JAMA 1998;280: 1510-7.

34. Stovall TG, Ling FW, Morgan PL. A prospective, randomized comparison of the Pipelle endometrial sampling device with the Novak curette. Am J Obstet Gynecol 1991;165(5 pt 1):1287-90. 
35. Bettocchi S, Ceci O, Vicino M, Marello F, Impedovo L, Selvaggi L. Diagnostic inadequacy of dilatation and curettage. Fertil Steril 2001;75:803-5.

36. Gimpelson RJ. Panoramic hysteroscopy with directed biopsies vs. dilatation and curettage for accurate diagnosis. J Reprod Med 1984;29:575-8.

37. Fleischer AC, Wheeler LE, Lindsay I, Hendrix SI, Grabill S, Kravitz B. An assessment of the value of ultrasonographic screening for endometrial disease in postmenopausal women without symptoms. Am J Obstet Gynecol 2001;184:70-5.

38. Apgar BS, Greenberg G. Using progestins in clinical practice. Am Fam Physician 2000;62:1839-46, 1849- 50.

39. DeVore GR, Owens O, Kase N. Use of intravenous Premarin in the treatment of dysfunctional uterine bleeding - a doubleblind randomized controlled study. Obstet Gynecol. 1982 Mar;59(3):285-91

40. Bettochi S, Nappi L, Ceci O, et al. Office hysteroscopy. Obstetrics and gynecology clinics of North America: advances in laparoscopy and hysteroscopy techniques, Philadelphia: W.B. Saunders Company; 2004. p. 641-54.

41. Schwarzler P, Concin H, Bosch H. An evaluation of sonohysterography and diagnostic hysteroscopy for assessment of intrauterine pathology. Ultrasound Obstet Gynecol. 1998; 11: 337-42.

42. Hamou JE. Microhysteroscopy: a new procedure and its original applications in gynecology. J Reprod Med1981;26:375-82

43. Pasqualotto EB, Margossian H, Price LL. Accuracy of preoperative diagnostic tools and outcome of hysteroscopic management of menstrual dysfunction. J Am Assoc Gynecol Laparosc. 2000;7:201-9.

44. Baggish MS, Barbot J. Contact hysteroscopy. Clin Obstet Gynecol. 1983;26:219-41.
45. Bhattacharya BK. Hysteroscopy for gynaecologic diagnosis. J Obstet Gynecol India. 1992;42:373-5.

46. Cicinelli E, Romano F, Anastasio PSl. Sonohysterography versus hysteroscopy in the diagnosis of endouterine polyps. Gynecol Obstet Invest. 1994;38:266-71.

47. T P Medina, E C Font. Diagnostic and Operative Hysteroscopy, $2^{\text {nd }}$ edition,2011,Pub: JPBMP.

48. Downes E, al Azawi F: How well do perimenopausal patients accept outpatient hysteroscopy? Visual analogue scoring of acceptability and pain in 100 women. Eur J Obstet Gynecol Teprod Biol 48:37, 1993.

49. Wheeler JM, DeCherney AH: Office hysteroscopy. Obset Gynecol Clin North Am 15:29, 1988.

50. Farquhar C, Ekeroma A, Furness S. A systematic review of transvaginal ultrasonography, sonohysterography and hysteroscopy for the investigation of abnormal uterine bleeding in premenopausal women. Acta Obstetricia et Gynecologica

Scandinavica. 2003;82(6):493-504.

51. Chaudhari KR, Parul Sathe. Role of diagnostic hysteroscopy in evaluation of abnormal uterine bleeding and its histopathological correlation Int $\mathbf{J}$ Reprod Contracept Obstet Gynecol. 2014 Sep;3(3):666-670, DOI: 10. $5455 / 2320$

1770.ijrcog20140958

52. S Bettochi, O Ceci, R,Di Venere, M.V. Pansini, A.Peliegrino, F.Marello and L.Nappi. Advanced office hysteroscopy without anesthesia: Analysis of 501 cases. Human reproduction Vol-17 No-9 pp 2435-2438,2002.

53. Jyotsana, Kamlesh Manhas, Sudha Sharm, Role of Hysteroscopy and Laparoscopy in Evaluation of Abnormal Uterine Bleeding, JK science, Vol. 6 No. 1, January-March 2004. 
54. Guin Gita, Sandhu Surpreet Kaur, Lele Arvind, Khare Shashi. Hysteroscopic evaluation of AUB, The Journal of Obstetrics and Gynecology of India, (September-October 2011), 61(5):546549,DOI:10.1007/s13224-011-0088-6.

55. Van Dongen H,De Kroon CD, Jacobi CE, Trimbos JB, Jansen FW. Diagnostic hysteronscopy in abnormal uterine bleeding: a systematic review and meta analysis. BJOG. 2007 Jun; 114(6):664-75. 